\title{
Influence of the interphase between laser-cladded metal layer and steel substrate on the fatigue propagation of a short edge crack
}

\author{
Lucie Malíková, Petr Miarka, Stanislav Seitl
}

Czech Academy of Sciences, Institute of Physics of Materials, v. v. i., Žǐ̌kova 22, 61600 Brno, Czech Republic, and Brno University of Technology, Faculty of Civil Engineering, Institute of Structural Mechanics, Veveri 331/95, 60200 Brno,

Czech Republic

malikova.l@fce.vutbr.č, http:/ /orcid.org/0000-0001-5868-5717

petr.miarka@vut.cz, http://orcid.org/0000-0002-4953-4324

seitl@ipm.cz,http://orcid.org/0000-0002-4953-4324

\section{Pavel Doubek}

Brno University of Technology, Faculty of Civil Engineering, Institute of Structural Mechanics, Veveř 331/95, 60200 Brno, Czech Republic, and OMNI-X CZ s.r.o., Samalova 60a, 61500 Brno, Czech Republic

pavel.doubek@omni-x.č,bttp://orcid.org/0000-0002-3010-8771

ABSTRACT. Laser cladding is a relatively new technology used to combine properties of various materials. As a result, bi-material interfaces now occur in real structures and can affect fatigue crack propagation. A cracked bar subjected to pure tensile loading is numerically simulated in this work in order to analyze the effect of the interphase layer between the cladded metal layer and the steel substrate on crack growth in the surface layer. Particularly, the influence of various Young's moduli of the interphase on stable/ unstable edge crack propagation is assessed. Moreover, the number of cycles necessary for the achievement of the defined critical crack length is calculated, and it is concluded that a good knowledge of the elastic properties of the thin interphase is crucial for fracture and fatigue analyses.

KEYWORDS. Laser cladding; Bi-material; Interphase; Fatigue crack propagation; Fracture mechanics; Edge crack.

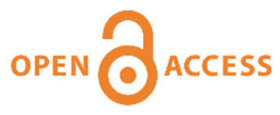

Citation: Malíková, L., Miarka, P., Doubek, P., Seitl, S., Influence of the interphase between laser-cladded metal layer and steel substrate on the fatigue propagation of a short edge crack, Frattura ed Integrità Strutturale, 59 (2022) 514-524.

Received: 15.11.2021

Accepted: 15.12 .2021

Published: 01.01.2022

Copyright: (C) 2022 This is an open access article under the terms of the CC-BY 4.0, which permits unrestricted use, distribution, and reproduction in any medium, provided the original author and source are credited.

\section{INTRODUCTION}

ecent works, such as [1,2], show that a great many structures combining often contradictory properties are becoming ever more common in technical practice. There exist different approaches to the interconnection of various materials and their dissimilar properties, e.g., particulate fiber and layered composites. The method investigated in 
this paper is laser cladding [3], which is especially appropriate for metallic materials, and steels in particular. Materials which are commonly applied through laser cladding are tool steel, types of stainless steel ( $\mathrm{Fe}, \mathrm{Cr}, \mathrm{Ni})$, cobalt, copper, nickel, and aluminum alloys. It is advantageous that laser cladding can be utilized either during the design process or when performing the renovation/repair of structures [4]. Its principle consists in the cladding of a base material whose properties are insufficient for the particular practical application with a relatively thin layer of an additional material with required properties. The protective layer can improve the mechanical and/or chemical properties of the surface (hardness, abrasion resistance, slip resistance, surface corrosion resistance, temperature resistance, etc.), which can generally lead to the extension of the service life of the component.

During the laser cladding procedure, a metal powder or wire is fed to a laser beam. This powder/wire is then melted together with the base material and a deposition layer is generated on the surface of the component [5,6]. A strong metallurgical bond is produced between the new metallic surface layer and the material of the substrate, see Fig. 1. The desired properties can be achieved via the appropriate selection and control of processing parameters such as laser beam power density, laser beam travel speed, and laser beam diameter at the workpiece surface. The main benefits of laser cladding can be summarized as the excellent adhesion it provides between the surface layer and the original structure, the small heat-affected zone, the relatively low dilution rate and the high variability in functional layers [7]. As stated above, the laser cladding method is suitable for creating functional surfaces with specific properties as well as for carrying out high-quality repairs of components damaged during the manufacturing process (due to errors and/or accidents) or through wear and tear. The technology can be utilized on highly stressed components (or their parts), such as forming tools, shear edges, leading edges of turbine blades, pins, stops, etc. The cladded layers can also provide protection against chemical effects [8] or high temperatures [9]. Laser cladding and similar procedures can be highly recommended, and can supplement or even replace some older technologies that are ecologically disadvantageous. Today, many recent scientific works are devoted to investigations into the behavior of metal layers [10-13].

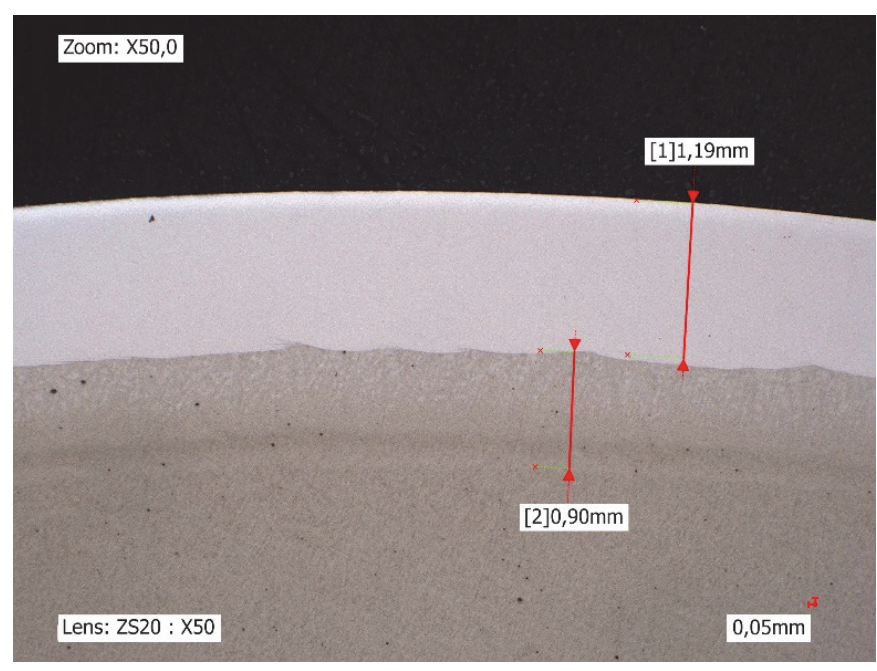

(a)

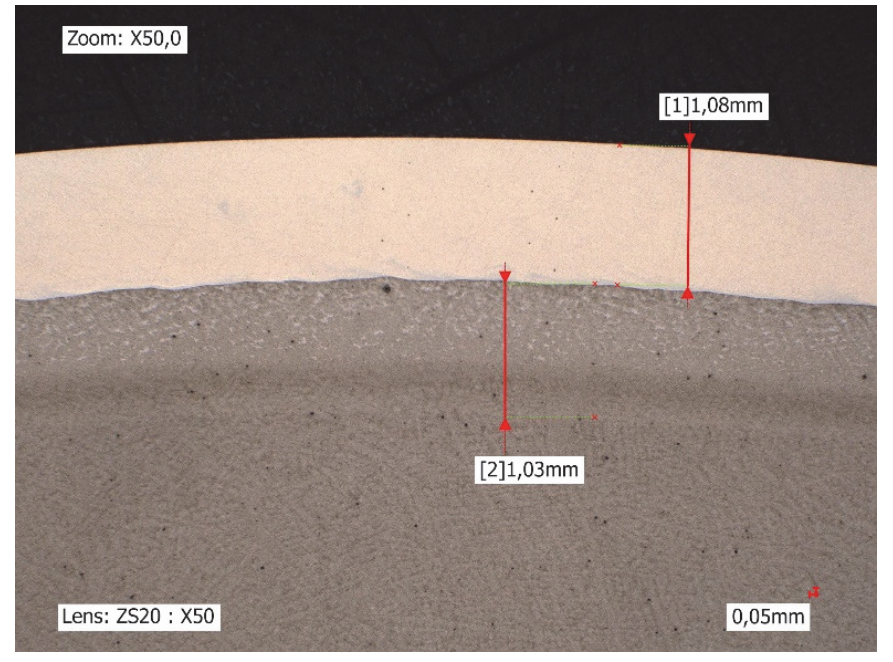

(b)

Figure 1: Detail of $50 \times$ zoomed cylindrical specimens made of structural steel with (a) a hard chrome layer; (b) an aluminum bronze layer applied via laser cladding.

Although the surface layer has improved properties in comparison to the substrate, it can contain defects and/or cracks that are able to reduce the lifetime of the whole component. Therefore, it is necessary to assess the fracture response of such components. Unlike in the case of crack propagation in a homogeneous material, the bi-material interface plays an important role when crack propagation is investigated in specimens with a thin protective layer. The sharp mutual difference in elastic properties between the individual materials influences the stress distribution in the specimen, and therefore also crack propagation. Moreover, an interphase layer can be observed between the laser cladded material and the basic material, as can also be seen in Fig. 1. While the Poisson's ratio has a rather negligible effect (documented in [14,15]), the influence of the Young's moduli mismatch is more substantial [16]. A parametrical study is presented within this paper in order to describe these effects on crack behaviour. A small fatigue crack inside the protective layer is considered, and linear elastic fracture mechanics approaches are assumed and applied. Note that these investigations are an initial part of intended upcoming research in the field of laser-cladded metal layers. 


\section{THEORETICAL BACKGROUND}

A

thin layer applied to a massive substrate by laser cladding to improve selected properties of a specimen can obtain various defects whose behavior can affect the reliability and lifetime of the whole component. These defects could arise in the cladded layer during the laser cladding process. Some defects are minor, but others may have a significant impact on the safe function of components or structural elements. Defects can be both on the surface or internal. These include cracks, end craters, pores, bubbles, inclusions, etc. They may be caused by many circumstances, e.g., by the chemical composition of the base or additive material, moisture, impurities, poor choice of welding parameters (e.g., high welding speed) or another type of failure to follow technical procedures correctly (e.g., insufficient preheating, high cooling rate, etc.).

In the case of samples with a laser welded layer, a non-destructive capillary test was performed on the subsequently partially machined surface according to ČSN EN ISO 23277. In some samples, minor material defects with a depth of 0.6 to $0.8 \mathrm{~mm}$ were detected (see Fig. 2). These defects could affect the initiation and propagation of fatigue cracks.

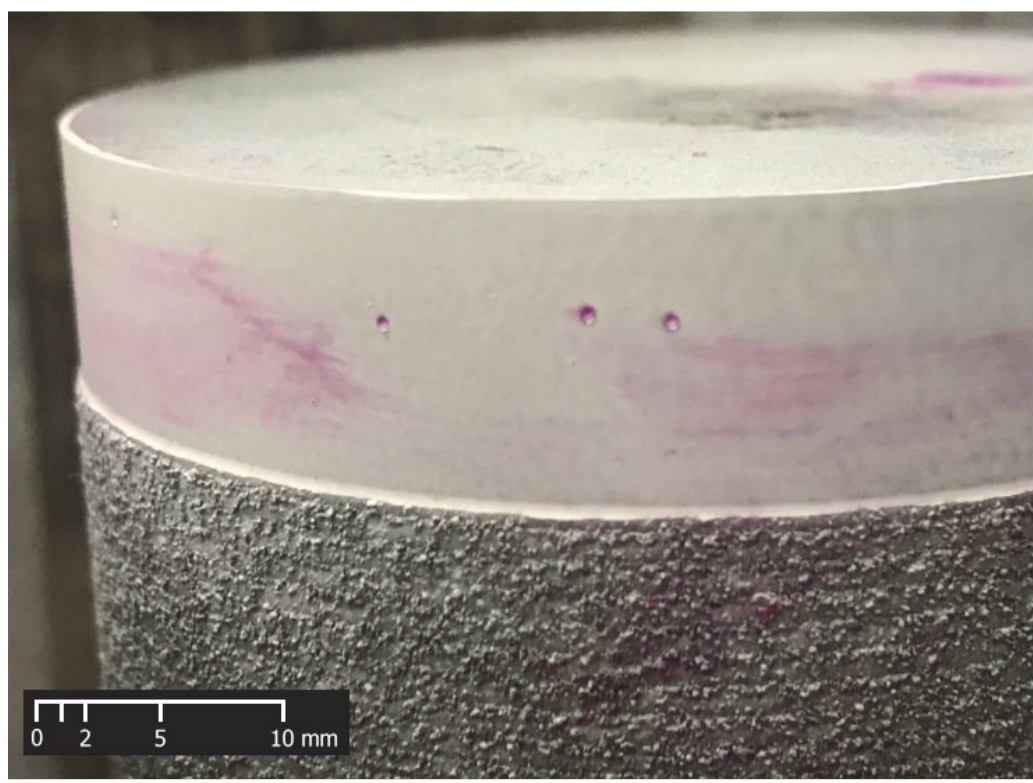

Figure 2: Minor material defects on a partially machined surface formed from laser cladded hard chrome.

Specimens can generally be subjected to static or cyclic loading - the latter option is investigated in this paper with regard to the real application of components. Thus, fatigue crack propagation is expected and shall be assessed via the usual methods. The fatigue crack growth rate for applied loading is defined by the increment of the crack length for a given number of loading cycles. Paris' law [17], also known as the Paris-Erdogan equation, is often used for the description of crack growth:

$$
\frac{\mathrm{d} a}{\mathrm{~d} N}=C(\Delta K)^{m}
$$

where $\mathrm{d} a / \mathrm{d} N$ is the fatigue crack growth rate, $\mathrm{d} a$ is the increment of crack length, $\mathrm{d} N$ is the number of cycles, $\Delta K$ is the stress intensity factor range ( $\Delta K=K_{\max }-K_{\min }$ ), and constants $C$ and $m$ are the experimentally obtained material coefficients for a given stress ratio $R=K_{\min } / K_{\max }$. Then, the number of load cycles to failure $\left(N_{\mathrm{f}}\right)$ can be calculated by integrating the crack propagation between an initial crack length $a_{0}$ and critical crack length $a_{\mathrm{c}}$ :

$$
N=\int_{a_{0}}^{a_{c}} \frac{\mathrm{d} a}{C(\Delta K)^{m}}
$$


The first step when the lifetime of a specimen is to be investigated for various elastic properties of the protective layer is the calculation of calibration curves, i.e., the dependences between the stress intensity factor range $\Delta K_{\mathrm{I}}$ and the (relative) crack length, see [18] for more details. These curves are obtained numerically via the finite element (FE) method when a specimen with a surface layer containing a short fatigue crack is subjected to pure tensile loading.

\section{GEOMETRY, MATERIAL PROPERTIES AND NUMERICAL MODEL}

he geometry of the finite element model has been designed with regard to the dimensions of the real specimens used for these investigations, see Fig. 3. These specimens are prepared with a view to comparing the results of their future testing with the results of numerical simulations. It should be noted that machining of the surface (and sometimes also annealing) is necessary after laser cladding.

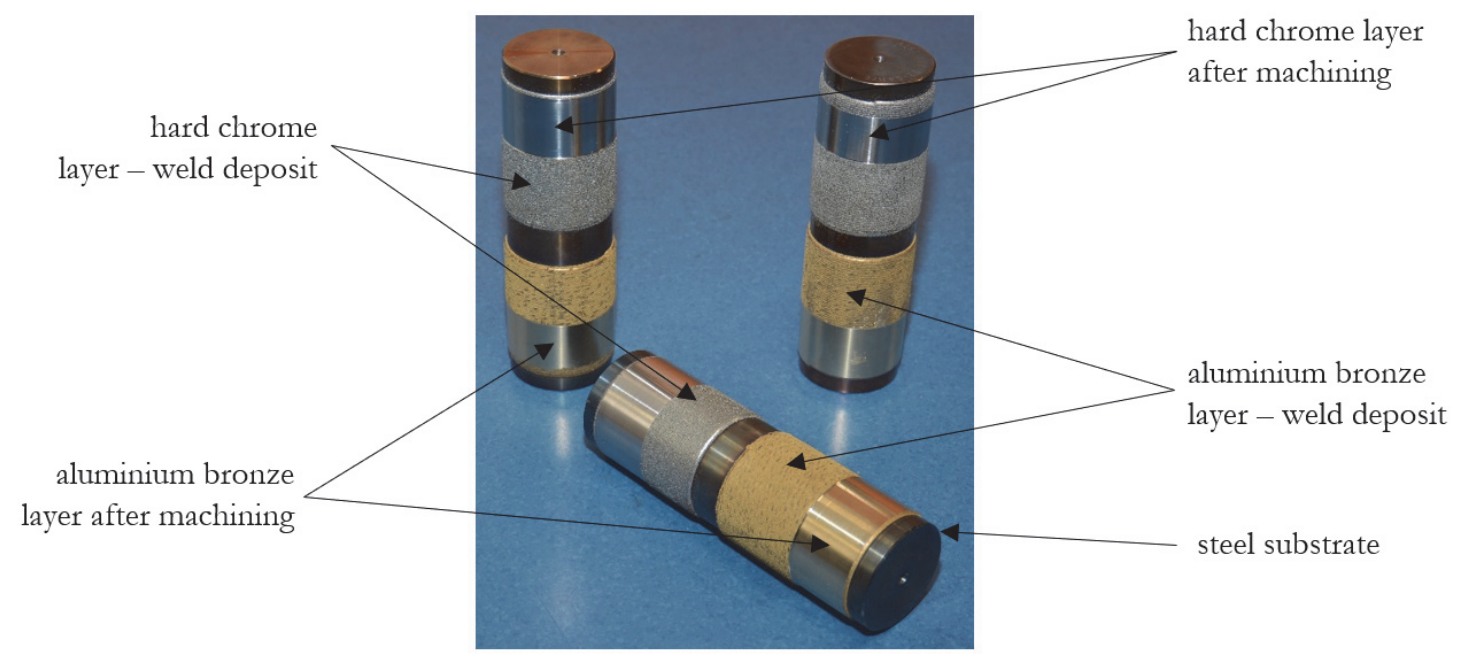

Figure 3: Real cylindrical specimens composed of steel substrate with a diameter of $60 \mathrm{~mm}$ and a length of $145 \mathrm{~mm}$ coated with a hard chrome layer and an aluminum bronze layer (both in the weld deposit state and after machining).

The surface coatings are produced via laser cladding, with one or two thin layers being applied depending on the required final surface coating thickness. Whereas in [19] the influence of various laser-cladded layer thicknesses on crack behavior was investigated, a specific thickness of $1 \mathrm{~mm}$ is considered in this work. Moreover, as can be seen in Fig. 1, a thin interphase layer is present between the steel substrate and the surface metal layer. Thus, it is considered to be a part of the numerical model as well. A schematic of the cracked specimen modelled in the ANSYS commercial FE system [20] can be seen in Fig. 4.

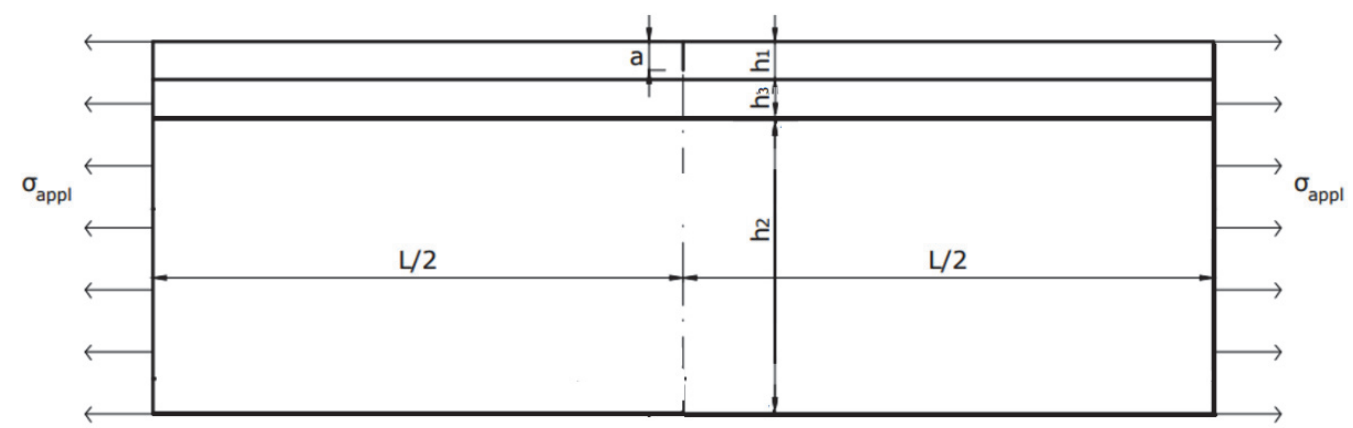

Figure 4: Schematic of a cracked bar subjected to pure tension; $h_{1}$ corresponds to the laser-cladded metal layer, $h_{2}$ represents the steel substrate and $h_{3}$ denotes the interphase layer. 
The geometry and material property values were chosen with regard to a previous study by the authors of this work [19] and are presented in Tab. 1.

\begin{tabular}{ccc}
\hline Parameter & Value & Unit \\
Young's modulus of the cladded layer, $E_{1}$ & 100 or 300 & $\mathrm{GPa}$ \\
Young's modulus of the steel substrate, $E_{2}$ & 200 & $\mathrm{GPa}$ \\
Young's modulus of the interphase layer, $E_{3}$ & various & $\mathrm{GPa}$ \\
Poisson's ratio of all materials, $v_{1}=v_{2}=v_{3}$ & 0.3 & - \\
Thickness of the cladded layer, $h_{1}$ & 1 & $\mathrm{~mm}$ \\
Thickness of the steel substrate, $h_{2}$ & 40 & $\mathrm{~mm}$ \\
Thickness of the interphase layer, $h_{3}$ & 1 & $\mathrm{~mm}$ \\
Relative crack length, $a / h$ & $0.1 \div 0.98$ & $\mathrm{~mm}$ \\
Bar specimen length, $L$ & 120 & $\mathrm{~mm}$ \\
Applied tensile stress, $\sigma_{\text {appl }}$ & 800 & $\mathrm{MPa}$
\end{tabular}

Table 1: Parameters of the numerical model used within the FE simulations: elastic material properties, geometry and applied loading.

Note that the Young's modulus of the cladded metal layer has been chosen to be 100 and $300 \mathrm{GPa}$, as these are the limit values corresponding to the elastic properties of the materials most commonly applied as a surface layer: hard chrome $(E \sim$ $100 \mathrm{GPa})$, aluminum bronze $(E \sim 115 \mathrm{GPa})$, high strength copper beryllium alloys $(\mathrm{E} \sim 130 \mathrm{GPa})$, cobalt alloys $(\mathrm{E} \sim 210$ $\mathrm{GPa}$ ), etc. $E_{1}=300 \mathrm{GPa}$ was considered for the mutual comparison of the results. The idea was to determine whether a stiffer cladded layer could have some advantages regarding fatigue crack propagation. The Young's modulus of the interphase layer varied between the Young's modulus of the surface layer and that of the steel substrate, i.e., $E_{3}=100,120$, 140, 160, 180 and $200 \mathrm{GPa}$ when $E_{1}=100 \mathrm{GPa}$, and $E_{3}=300,280,260,240,220$ and $200 \mathrm{GPa}$ when $E_{1}=300 \mathrm{GPa}$. The applied tensile loading value was suggested in accordance with real conditions in practice where structures are subjected to approx. $800 \mathrm{MPa}$. The interphase thickness value was suggested based on the microscopic observations of real specimens. It can be seen in Fig. 1 that the thickness of the interphase is similar to that of the surface metal layer, whose thickness is about $1 \mathrm{~mm}$. Therefore, the thickness of the interphase layer is also close to the used value of $1 \mathrm{~mm}$.

Material fatigue calculations are performed for Aluminium Bronze Thermal Spray Powder applied to a steel base via the laser cladding technique. For other stated laser cladded materials (hard chrome, Stellite and so on), it is currently very difficult to determine the relevant material constants $C$ and $m, \mathrm{y}$, and they are not as well-known as those for steels, see e.g. S355 [21], S690 [22], and AISI 304 [23]. We are therefore planning to perform our own experimental determination of these constants, and also further fatigue calculations for other material combinations. The chemical composition of the aluminum alloy as well as other input parameters necessary for calculations of specimen lifetime are presented in Tabs. 2 and 3. The material constants $C$ and $m$ for stress ratio $R=0$ were taken from [24].

\begin{tabular}{cc}
\hline Element & Weight percent \\
$\mathrm{Cu}$ & Bal. \\
$\mathrm{Al}$ & $8.5-10.75$ \\
$\mathrm{Fe}$ & $0.5-2.0$ \\
Others (max) & 0.5 \\
\hline
\end{tabular}

Table 2: Chemical composition of Aluminum Bronze Thermal Spray Powder in weight percent (nominal). 


\begin{tabular}{ccc}
\hline Parameter & Value & Unit \\
Initial crack length, $a_{0}$ & 0.6 & $\mathrm{~mm}$ \\
Critical crack length, $a_{\mathrm{c}}$ & 1.0 & $\mathrm{~mm}$ \\
Material constant, $C$ & $1.63 \mathrm{E}-10$ & $(\mathrm{~mm} / \mathrm{cycle}) /\left(\mathrm{MPa} \cdot \mathrm{m}^{1 / 2}\right)^{m}$ \\
Material constant, $m$ & 3.2 & - \\
Factor of safety, FOS & 2 & - \\
Stress ratio, $R$ & 0 & - \\
\hline
\end{tabular}

Table 3: Input parameters applied within the calculations of the service lifetime for aluminum bronze.

The cracked bar under pure tensile loading has been modeled in ANSYS FE software. Because of the symmetry of the bar, only one half of the model needed to be created, during which the corresponding boundary conditions was applied. Perfect adhesion was considered between the individual materials. The specimen was meshed via quadrilateral 8-node elements (PLANE183), with finer elements concentrated around the crack tip. The crack-tip singularity was modelled through the shifted mid-side nodes of the first row of the elements around the crack tip (the implemented KSCON command was applied), see Fig. 5. The crack was subjected to pure opening mode I via the application of tensile stress on both ends of the specimens, as can be seen in Fig. 4. The FE model was calibrated as homogenous with data for a single edge cracked plate tension specimen from the handbook [25]. Thus, the convergence of the results regarding their sensitivity to the element size was also investigated. Moreover, values were calculated for the stress intensity factor range via the CINT command, and its independence from the crack path chosen for the integration was verified. All these steps enabled the suggested numerical model to be considered suitable and correct for the analysis performed. In addition to this, to find the optimum mesh size for further analysis, the stress intensity factor results were compared with each other. If the SIF result of different mesh sizes was less than $1 \%$, the mesh size was selected as being appropriate for further calculations. The chosen mesh is presented in Fig. 5.

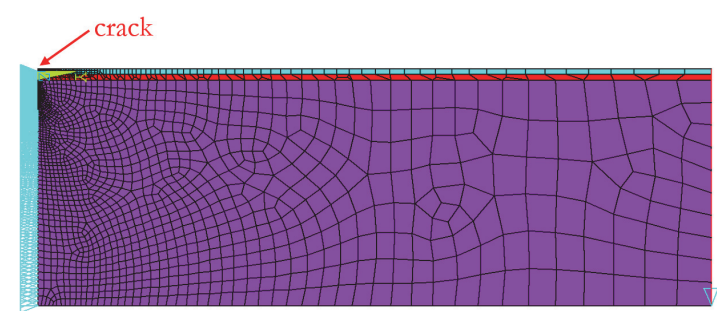

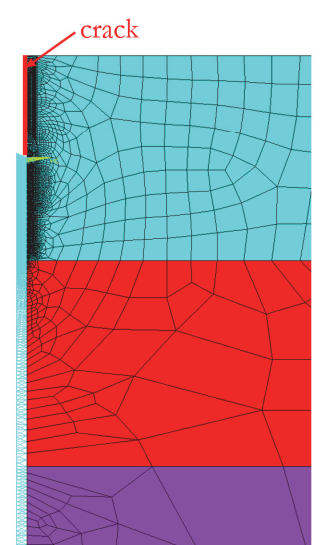

(b) (a)

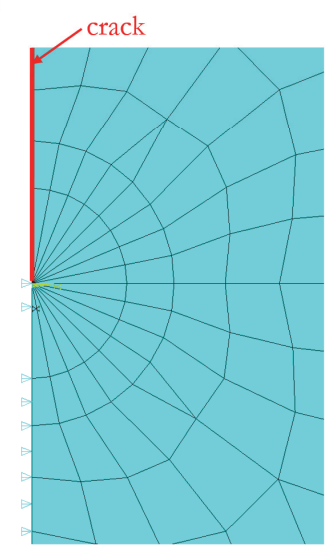

(c)

Figure 5: FE numerical model of the cracked specimen with applied boundary conditions (steel substrate - violet, interphase - red, cladded metal layer - turquoise): (a) the whole single half of the specimen modeled; (b) detail of the crack in the cladded metal layer; (c) detail of the crack tip with shifted mid-side nodes of the first row of elements. 
Thus, the numerical modeling procedure performed to obtain the dependences of the stress intensity factor range on the crack length for various material combinations was followed by the procedure for the calculation of the number of cycles to failure. A flow chart describing the procedure for crack growth analysis is presented in Fig. 6.

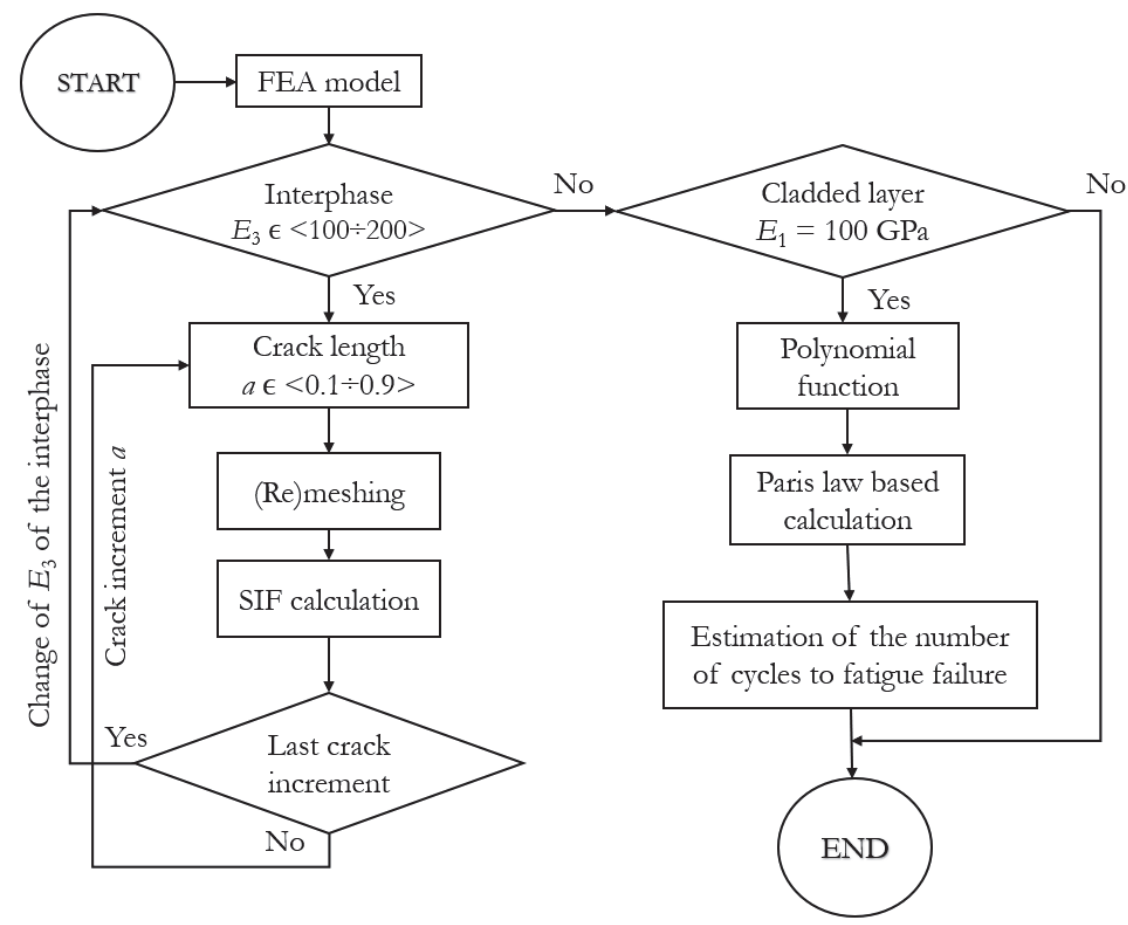

Figure 6: Flow chart describing the procedure for crack growth analysis.

\section{RESULTS AND DISCUSSION}

I $\mathrm{n}$ the following section, the results obtained from the parametric numerical study are presented. When stable/unstable crack propagation is assessed, the values of the threshold stress intensity factor range and the critical stress intensity factor range need to be known. The former of these decides if the crack will even start to propagate (in a stable manner, i.e., slowly and in a rather controllable way), and the latter defines the value necessary for unstable crack propagation, when the crack propagates very fast through the whole specimen and causes the unexpected failure of the specimen. An example of values of the threshold stress intensity factor range $\Delta K_{\mathrm{Ith}}=3.5 \mathrm{MPa} \cdot \mathrm{m}^{1 / 2}$ and the critical stress intensity factor range $\Delta K_{\mathrm{IC}}=22.5 \mathrm{MPa} \cdot \mathrm{m}^{1 / 2}$ is considered, see Fig. $7 \mathrm{a}$. These values are typical for aluminum alloys and can vary in the range of approximately $3 \div 4 \mathrm{MPa} \cdot \mathrm{m}^{1 / 2}$ for $\Delta K_{\text {Ith }}$ [26] and $20 \div 25 \mathrm{MPa} \cdot \mathrm{m}^{1 / 2}$ for $\Delta K_{\text {IC }}$ [27]. Note that the results can be modified for

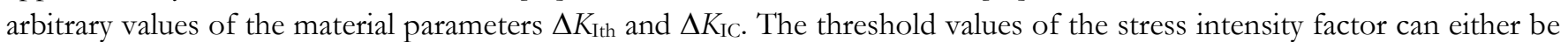
measured experimentally or can be found in the literature, see e.g., [28] for aluminum, [29] or [30] for steel, [31] for high strength steel, etc. The results presented in Fig. 7 a were obtained for the interphase layer with an elastic modulus of $E_{1}=100 \mathrm{GPa}$, whereas Fig. 7b introduces the results for the interphase layer with an elastic modulus of $\mathrm{E}_{1}=300 \mathrm{GPa}$. The results presented in Fig. 7a enable the formulation of the following statements:

- Because all the calibration curves are above the value of $\Delta K_{\text {Ith }}$, even very short surface cracks will propagate through the cladded metal layer in a stabile manner.

- Unstable crack propagation is more likely when the interphase layer has the elastic properties of the surface layer, or similar properties, i.e., it stays more compliant in comparison to the steel substrate.

- A crack of the length of 0.7 to $0.9 \mathrm{~mm}$ will grow unstably if the Young's modulus of the interphase layer is about 100 to $140 \mathrm{GPa}$.

- On the other hand, if the interphase layer is rather stiff, i.e., it has an elastic modulus similar to that of the steel substrate (200 GPa or slightly lower), unstable crack growth does not occur in the surface layer at all. 
- Some of the curves (for instance when $E_{3}=140$ to $200 \mathrm{GPa}$ ) show that if the critical value of the stress intensity factor range $\Delta K_{\mathrm{IC}}$ of the protective layer is slightly lower, unstable crack growth can stop after some time, and crack elongation and the phase of stable crack growth can occur again. This phenomenon is connected to the curvature of the calibration curve near the interface between the cladded metal layer and the interphase.

- It is therefore very important to have a good knowledge of the elastic properties of the interphase layer between the cladded metal layer and the steel substrate when crack propagation in such kinds of materials is assessed.

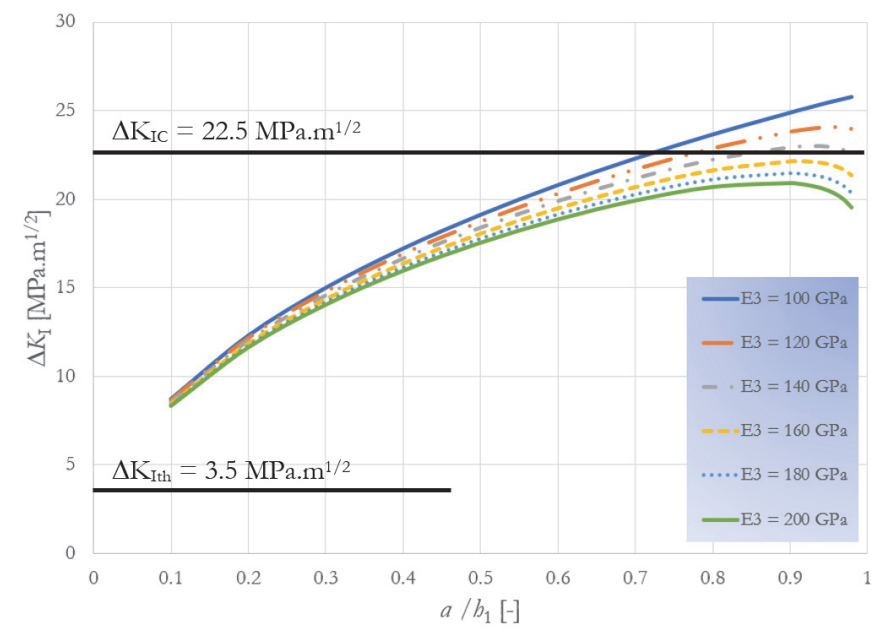

(a)

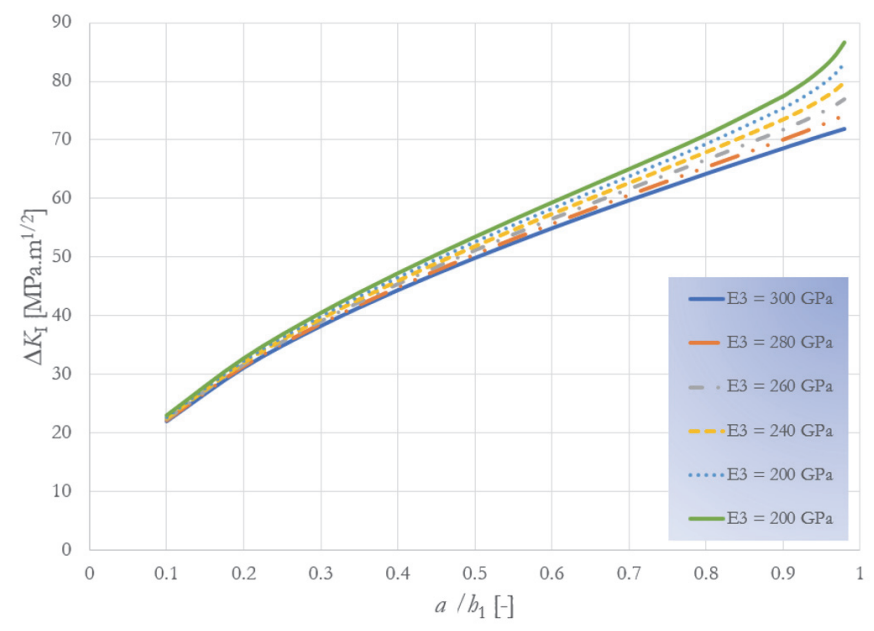

(b)

Figure 7: Dependence of the stress intensity factor range on the relative crack length for various elastic properties of the interphase layer while considering the Young's modulus of the cladded metal layer (a) $E_{1}=100 \mathrm{GPa}$; (b) $E_{1}=300 \mathrm{GPa}$.

Similar dependences were calculated for the case when the material of the surface layer is stiffer than the steel substrate. Again, the influence of the elastic properties of the interphase on crack propagation was investigated. The results can be seen in Fig. 7b, and the following conclusions can be stated:

- The values of the stress intensity factor range are considerably higher than in Fig. 7a because of the higher Young's modulus of the cladded metal layer.

- Considering the same values of $\Delta K_{\text {Ith }}$ and $\Delta K_{\text {IC }}$ as in Fig. 7 a would mean that even short cracks (about $0.1 \mathrm{~mm}$ ) would propagate unstably through the protective layer.

- On the other hand, it can be expected that a material with a Young's modulus of $300 \mathrm{GPa}$ will have higher values of the fatigue parameters $\Delta K_{\mathrm{Ith}}$ and $\Delta K_{\mathrm{IC}}$.

The results obtained clearly show that the elastic properties of the surface layer and interface layer play an important role in the crack propagation process. Thus, the material of the cladded layer can be chosen with regard to the conclusions, and moreover, the parameters of the technology can be changed in order to influence the properties of the interphase layer and improve the fatigue/fracture response of the specimen/structure.

An additional analysis was performed regarding the number of cycles necessary for crack propagation from the initial crack length of $0.6 \mathrm{~mm}$ to the critical crack length of $1 \mathrm{~mm}$, i.e., through the whole cladded metal layer. The influence of the elastic properties of the interphase layer was investigated. The results obtained are presented in Tab. 4 for the case of the Young's modulus of the protective layer $\mathrm{E}_{1}=100 \mathrm{GPa}$. Note that the polynomials obtained from the dependences presented in Fig. 7a were used as inputs for the integral defined through Eq. 2: they are presented in Tab. 5.

The numbers of cycles $\left(N_{\mathrm{f}}, N_{\mathrm{FOS}}=2\right)$ presented in Tab. 4 clearly show that the elastic properties of the interphase layer have a significant effect on fatigue crack propagation. When the interphase is stiffer, a higher number of cycles is necessary for crack growth from 0.6 to $1 \mathrm{~mm}$. Particularly, there is a $60 \%$ increase in the $N_{\mathrm{FOS}=2}$ when the Young's modulus of the interphase is $200 \mathrm{GPa}$ in comparison to $100 \mathrm{GPa}$. Analogically, this kind of calculation can be performed for an arbitrary combination of materials. In order to assess the lifetime of a component reliably, knowledge of the elastic properties of the interphase layer is crucial. Note that an experimental campaign is currently being prepared in order to be able to compare the results of the numerical simulations with experimentally obtained data. 


\begin{tabular}{ccc}
\hline Young's modulus of the interphase [GPa] & $N_{\mathrm{f}}$ [cycles] & $N_{\mathrm{FOS}=2}$ [cycles] \\
100 & 102349 & 51175 \\
120 & 114769 & 57385 \\
140 & 127107 & 63554 \\
160 & 139859 & 69930 \\
180 & 152130 & 76065 \\
200 & 164333 & 82167 \\
\hline
\end{tabular}

Table 4: $N_{\mathrm{f}}$ is the expected number of cycles to failure (considering crack propagation from the initial crack length of $0.6 \mathrm{~mm}$ to the critical crack length of $1 \mathrm{~mm}$ in the aluminum bronze surface layer) and $N_{\mathrm{FOS}=2}$ is the number of cycles that the part will experience in service.

\begin{tabular}{ccc}
\hline $\begin{array}{c}\text { Young's modulus } \\
\text { of the interphase } \\
{[\mathrm{GPa}]}\end{array}$ & $\begin{array}{c}\text { Polynomial function } f(a) \mathrm{f} \text { or } \Delta K_{\mathrm{I}}\left[\mathrm{MPa} \cdot \mathrm{m}^{1 / 2}\right] \\
100\end{array}$ & $\begin{array}{c}\text { Index of dispersion } \\
\mathrm{R}^{2}[-]\end{array}$ \\
120 & $-23.575 a^{4}+75.532 a^{3}-96.296 a^{2}+70.286 a+0.0407$ & 0.999 \\
140 & $-535.49 a^{4}+1613.3 a^{3}-1822.3 a^{2}+924.76 a-158.02$ & 0.998 \\
160 & $-690.37 a^{4}+2077.7 a^{3}-2342.9 a^{2}+1182.1 a-205.65$ & 0.997 \\
180 & $-806.65 a^{4}+2425.9 a^{3}-2733 a^{2}+1374.8 a-241.31$ & 0.995 \\
200 & $-895.64 a^{4}+2692.2 a^{3}-3031.1 a^{2}+1521.9 a-268.56$ & 0.993 \\
\hline
\end{tabular}

Table 5: Polynomials for $\Delta K_{\mathrm{I}}$ as functions of the crack length $a_{1}$ for various values of the elastic modulus of the interphase layer.

\section{CONCLUSIONS}

7 he fatigue crack behavior of a short crack in a thin metal layer laser-cladded on a steel substrate is investigated within this work. Particularly, a cracked bar under pure tensile loading is simulated numerically and the effect of the interphase layer on crack propagation is analyzed. A parametric study is performed in order to assess the influence of the elastic properties of the interphase on stable/unstable fatigue crack propagation. It is discovered that unstable crack propagation is more likely when the interphase layer has the elastic properties of the surface layer, or similar properties, i.e., it stays more compliant in comparison to the steel substrate. On the other hand, if the interphase layer is rather stiff, i.e., it has an elastic modulus which is similar to that of the steel substrate (200 GPa or slightly lower), unstable crack growth does not occur in the surface layer at all. Some of the curves presented in the previous section show that if the critical value of the stress intensity factor range $\Delta K_{\mathrm{IC}}$ of the protective layer is slightly lower, unstable crack growth can be stopped after some time and crack elongation and the phase of stable crack growth can occur again. Furthermore, when the interphase is stiffer, a higher number of cycles is necessary for the modeled crack growth. Particularly, there is a $60 \%$ increase in the $N_{\text {Fos }}$ when the Young's modulus of the interphase is $200 \mathrm{GPa}$ in comparison to $100 \mathrm{GPa}$. Thus, it can be concluded that it is very important to have a good knowledge of the elastic properties of the interphase layer between the cladded metal layer and the steel substrate when fatigue crack propagation in such kinds of materials is to be assessed. 


\section{ACKNOWLEDGMENTS}

$\mathrm{F}$ inancial support from the Faculty of Civil Engineering, Brno University of Technology (project No. FAST-S-217338) and project No. 21-14886S (Influence of material properties of high strength steels on the durability of engineering structures and bridges) is gratefully acknowledged.

\section{REFERENCES}

[1] Bhat, S., Adarsha, H., Ravinarayan, V., Koushik, V.P. (2019). Analytical model for estimation of energy release rate at mode I crack tip in bi-material of identical steels joined by an over-matched weld interlayer, Procedia Struct. Integr., 17, pp. 21-28, DOI: 10.1016/J.PROSTR.2019.08.004.

[2] Khodadad Motarjemi, A., Koçak, M., Ventzke, V. (2002). Mechanical and fracture characterization of a bi-material steel plate, Int. J. Press. Vessel. Pip., 79(3), pp. 181-191, DOI: 10.1016/S0308-0161(02)00012-1.

[3] Zhu, L., Xue, P., Lan, Q., Meng, G., Ren, Y., Yang, Z., Xu, P., Liu, Z. (2021). Recent research and development status of laser cladding: A review, Opt. Laser Technol., 138, DOI: 10.1016/J.OPTLASTEC.2021.106915.

[4] Li, M., Han, B., Song, L., He, Q. (2020). Enhanced surface layers by laser cladding and ion sulfurization processing towards improved wear-resistance and self-lubrication performances, Appl. Surf. Sci., 503, pp. 144226, DOI: 10.1016/J.APSUSC.2019.144226.

[5] Liu, P., Zhang, Y.B., Luo, H. (2013). Surface modification of pure Ti with TiB2/Si3N4 reinforced coating, Surf. Eng., 28(7), pp. 532-535, DOI: $10.1179 / 1743294412$ Y.0000000012.

[6] Wang, W., Chen, Z., Feng, S. (2019). Effect of CeO 2 on Impact Toughness and Corrosion Resistance of WC Reinforced Al-Based Coating by Laser Cladding, Mater. (Basel, Switzerland), 12(18), DOI: 10.3390/MA12182901.

[7] Shepeleva, L., Medres, B., Kaplan, W.D., Bamberger, M., Weisheit, A. (2000). Laser cladding of turbine blades, Surf. Coat. Technol., 1-3(125), pp. 45-48, DOI: 10.1016/S0257-8972(99)00603-9.

[8] Xu, J.S., Zhang, X.C., Xuan, F.Z., Tian, F.Q., Wang, Z.D., Tu, S.T. (2013). Tensile properties and fracture behavior of laser cladded WC/Ni composite coatings with different contents of WC particle studied by in-situ tensile testing, Mater. Sci. Eng. A, C(560), pp. 744-751, DOI: 10.1016/J.MSEA.2012.10.028.

[9] Chen, Y., Guo, Y., Xu, M., Ma, C., Zhang, Q., Wang, L., Yao, J., Li, Z. (2019). Study on the element segregation and Laves phase formation in the laser metal deposited IN718 superalloy by flat top laser and gaussian distribution laser, Undefined, 754, pp. 339-347, DOI: 10.1016/J.MSEA.2019.03.096.

[10] Duval-Chaneac, M.S., Gao, N., Khan, R.H.U., Giles, M., Georgilas, K., Zhao, X., Reed, P.A.S. (2021). Fatigue crack growth in IN718/316L multi-materials layered structures fabricated by laser powder bed fusion, Int. J. Fatigue, 152, pp. 106454, DOI: 10.1016/J.IJFATIGUE.2021.106454.

[11] Feng, J., Qin, Y., Liskiewicz, T.W., Beake, B.D., Wang, S. (2021). Crack propagation of a thin hard coating under cyclic loading: Irreversible cohesive zone model, Surf. Coatings Technol., 426, pp. 127776, DOI: 10.1016/J.SURFCOAT.2021.127776.

[12] Lv, J.N., Fan, X.L., Li, Q. (2017). The impact of the growth of thermally grown oxide layer on the propagation of surface cracks within thermal barrier coatings, Surf. Coatings Technol., 309, pp. 1033-1044, DOI: 10.1016/J.SURFCOAT.2016.10.039.

[13] Shasthri, S., Kausalyah, V. (2020). Effect of ballistic impact on Ti6Al-4V titanium alloy and 1070 carbon steel bi-layer armour panel, Int. J. Struct. Integr., 11(4), pp. 557-565, DOI: 10.1108/IJSI-09-2019-0095.

[14] Aslantas, K., Tasgetiren, S. (2002). Debonding between coating and substrate due to rolling-sliding contact, Mater. Des., 23(6), pp. 571-576, DOI: 10.1016/S0261-3069(02)00020-1.

[15] Delale, F., Erdogan, F. (1983). The crack problem for a nonhomogeneous plane, J. Appl. Mech. Trans. ASME, 50(3), pp. 609-614, DOI: 10.1115/1.3167098.

[16] Chiang, C.R. (1991). On the stress intensity factors of cracks near an interface between two media, Int. J. Fract., 47(4), DOI: $10.1007 / \mathrm{BF} 00012951$.

[17] Paris, P., Erdogan, F. (1963). A Critical Analysis of Crack Propagation Laws, J. Basic Eng., 85(4), pp. 528-533, DOI: $10.1115 / 1.3656900$.

[18] Anderson, T.L. (1995). Fracture mechanics: fundamentals and applications, Florida, CRC Press LLC.

[19] Malíková, L., Miarka, P., Doubek, P., Seitl, S. (2021). Influence of the bi-material interface on the crack propagation through a thin protective layer, Struct. Integr. Procedia. 
[20] ANSYS. (2021). ANSYS Program Documentation.

[21] Stanislav, S., Petr, M., Jan, K., Stanislava, F., Ludvík, K. (2018). Comparison of the Fatigue Crack Propagation Rates in S355 J0 and S355 J2 Steel Grades, DOI: 10.4028/www.scientific.net/KEM.784.91.

[22] De Jesus, A.M.P., Matos, R., Fontoura, B.F.C., Rebelo, C., Simões Da Silva, L., Veljkovic, M. (2012). A comparison of the fatigue behavior between S355 and S690 steel grades, J. Constr. Steel Res., 79, pp. 140-150, DOI: 10.1016/J.JCSR.2012.07.021.

[23] Seitl, S., Pokorný, P., Klusák, J., Duda, S., Lesiuk, G. (n.d.). Effect of specimen thickness on fatigue crack growth resistance in Paris region in AISI 304 STEEL, Fatigue Fract. Mater. Struct. Struct. Integr., in press.

[24] Carpinteri, A., Paggi, M. (2007). Are the Paris' law parameters dependent on each other?, Frat. Ed Integrità Strutt., 1(2), pp. 10-16, DOI: 10.3221/IGF-ESIS.02.02.

[25] Tada, H., Paris, P.C., Irwin, G.R. (2000). The Stress Analysis of Cracks Handbook, Third Edition, Stress Anal. Cracks Handbook, Third Ed., DOI: 10.1115/1.801535.

[26] Holper, B., Mayer, H., Vasudevan, A.K., Stanzl-Tschegg, S.E. (2004). Near threshold fatigue crack growth at positive load ratio in aluminium alloys at low and ultrasonic frequency: influences of strain rate, slip behaviour and air humidity, Int. J. Fatigue, 26(1), pp. 27-38, DOI: 10.1016/S0142-1123(03)00092-6.

[27] Doddamani, S., Kaleemulla, K.M. (2016). Review of experimental fracture toughness (KIC ) of aluminium alloy and aluminium MMCs, Int. J. Fract. Damage Mech., 1(2), pp. 38-51.

[28] Stanzl, S.E., Mayer, H.R., Tschegg, E.K. (1991). The influence of air humidity on near-threshold fatigue crack growth of 2024-T3 aluminum alloy, Mater. Sci. Eng. A, 147(1), pp. 45-54, DOI: 10.1016/0921-5093(91)90803-U.

[29] Suresh, S. (1998). Fatigue of Materials, Fatigue Mater., DOI: 10.1017/CBO9780511806575.

[30] Pokorný, P., Vojtek, T., Náhlík, L., Hutař, P. (2017). Crack closure in near-threshold fatigue crack propagation in railway axle steel EA4T, Eng. Fract. Mech., 185, pp. 2-19, DOI: 10.1016/J.ENGFRACMECH.2017.02.013.

[31] Li, H.F., Zhang, P., Wang, B., Zhang, Z.F. (2022). Predictive fatigue crack growth law of high-strength steels, J. Mater. Sci. Technol., 100, pp. 46-50, DOI: 10.1016/J.JMST.2021.04.042. 